\section{AIDS meeting calls for wider testing}

Washington

TESTING for AIDS (acquired immune deficiency syndrome) should be offered more aggressively to people in high-risk groups but should not be made compulsory. That is the conclusion of a conference sponsored by the Centers for Disease Control (CDC) in Atlanta last week.

The participants, including state and local public health officials and civil liberties advocates as well as representatives of some high-risk groups, met to discuss the role of serological testing in the prevention and control of AIDS. The CDC will evaluate the recommendations and issue its own report to the government in the next few weeks.

The biggest change that the conference participants advocated was a shift from passive to active testing in treatment centres for sexually transmitted diseases and intravenous drug users. Under this plan, people attending the centres would be tested for AIDS "routinely" unless they specifically objected.

The participants also called for greater confidentiality of test results and protection from discrimination of those tested. Although unauthorized release of test results does not seem to have occurred very frequently, some groups, particularly homosexuals, fear the repercussions of unauthorized release.

Nevertheless Franklyn N. Judson, director of public health in Denver and comoderator of a panel discussion at Atlanta, stressed the need for keeping confidential records of AIDS virus carriers. $\mathrm{He}$ pointed out that for years there have been confidential registries for people with other sexually transmitted diseases, and that it "would be irresponsible not to do this for AIDS". But Judson thinks it unlikely that the US government will issue regulations on confidentiality.

Judson said that cities such as Denver have begun screening blood from hetero sexuals who attend the treatment centres for sexually transmitted diseases. So far, all carriers of the AIDS virus have come from an identified high-risk group.

$\mathrm{CDC}$ are also conducting a long-term study of blood scheduled to be discarded from hospitals for evidence of AIDS virus antibodies in the hope of compiling data on the prevalence of infection. All patient identification data except for age and sex are removed before blood samples are tested. The hospitals involved are in both low- and high-prevalence areas. By using blood already due to be discarded, the CDC are able to avoid issues of consent.

\title{
Special Research Centres to continue in Australia
}

Sydney

THE Australian government is to continue to fund the Special Research Centres says Senator Susan Ryan, Minister for Education. The centres were previously known as 'Centres of Excellence' at their inception in 1982.

There are at present nine Special Research Centres, which last year received a total of A $\$ 6$ million. On the recommendation of a Commonwealth Tertiary Education Commission (CTEC) committee, Ryan has promised that funding for the programme will continue at least at the present level for the three years to 1990 . One and a half centres will lose their status as such this year and the rest will suffer cuts of around 10 per cent. The $\mathrm{A} \$ 1.5$ million saved will go to establish three new centres that will be announced in the federal budget in August. The new centres are likely to be in areas closely related to industry to increase exports of manufactured goods and to answer criticisms that the present distribution is biased towards medicine and biology.

To be cut off this year are the Centre of Policy Studies at Monash University headed by Professor Michael Porter and the group led by Professor R. Bruce Knox working on reproductive biology, which makes up half of the Plant Cell Biology Research Centre at the University of Melbourne, the surviving half being led by $\mathrm{Dr}$ Adrienne Clark, the only woman leader among the centres. The axing of Porter's centre was seen by the Conservative opposition as a blatant political move by the Labor government as the centre has been involved in modelling work for the development of tax policies for the opposition and right-wing groups. Ryan maintains that the move was taken purely on the advice of the CTEC committee which

concluded that the published work attributed to the centre of neither the quantity nor the standard required.

The Special Research Centres are opposed by the Federation of Australian University Staff Associations (FAUSA) which considers the centres' budget to be taken from that available for research by the average teaching academic.

The centres were established by the previous Conservative coalition government on the premise that applying concentrated money with guaranteed continuity to the nation's best brains would produce results far in excess of what might be achieved if the money were spent through normal channels. Dr James Beattie, associate professor in chemistry at Sydney University and chairman of the FAUSA Research Committee, points out that the CTEC review was conducted hurriedly with some the centre assessment panels complaining of lack of time.

According to Beattie, FAUSA would prefer to see the money spent on the general research infrastructure such as buildings, libraries and equipment, at present in a poor state. FAUSA would prefer the funds to be administered by the Australian Research Grants Scheme (ARGS) where the relative excellence of proposed research is subject to broad-based review by academic peers.

Each year, the ARGS distributes about 1,200 grants to a total Australian academic population of about 12,000 scientists. Alternatively, given that the average ARGS grant is worth $A \$ 20,000$, the A $\$ 6$ million of special research centre money would be enough to fund the work of the 300 researchers whose proposals the ARGS judged to be "excellent" but for which it had no money in 1986.

Charles Morgan

\section{Boost for Indian high-energy physics}

\section{New Delhi}

INDIAN physicists are making plans to build a 1-GeV proton synchrotron, to be followed by a 12-GeV Synchrotron, in an attempt to catch up with the West in highenergy physics research. The accelerators will be built at Indore, in Madhya Pradesh, where India is establishing the Centre for Advanced Technology (CAT) at a cost of some $\$ 100$ million.

The task of setting up CAT has been given to the Department of Atomic Energy (DAE), which says that the centre will focus on accelerators, lasers and laser technology for thermonuclear fusion. CAT is expected to become a major hightechnology centre in the next 20 years.
To start with, DAE hopes to build a synchrotron radiation source consisting of a $25-\mathrm{MeV}$ electron linear accelerator, a booster that will accelerate the electrons to $700 \mathrm{MeV}$, and two storage rings. The proton synchrotrons are aimed at producing anti-protons and kaons and studying the physics of condensed matter using heavy ions. India at present has a $100-\mathrm{MeV}$ cyclotron in Calcutta, a 5.5-MeV Van der Graaf machine and a 14-MeV pelletron in Bombay.

According to DAE, CAT will be the main research centre for work on laser fusion. CAT will also concentrate on associated fields such as cryogenics and radio frequency systems. K.S. Jayaraman 